\title{
Construct and face validity of SINERGIA laparoscopic virtual reality simulator
}

\author{
Luisa F. Sánchez-Peralta - Francisco M. Sánchez-Margallo · José Luis Moyano-Cuevas • \\ José Blas Pagador • Silvia Enciso-Sanz • Patricia Sánchez-González • \\ Enrique J. Gómez-Aguilera · Jesús Usón-Gargallo
}

\begin{abstract}
Purpose Laparoscopic techniques have nowadays become a gold standard in many surgical procedures, but they imply a more difficult learning skills process. Simulators have a fundamental role in the formative stage of new surgeons. This paper presents the constnct and tace validity of SINERGIA laparoscopic virtual reality simulator in order to decide whether it can be considered as an assessment tool.

Methods Twenty people participated in this study, 14 were novices and 6 were experts. Five tasks of SINERGIA were included in the study: coordination, navigation, navigation and touch, precise grasping and coordinate traction. For each one of these tasks, a certain number of metrics are autonatically recorded. All subjects accomplished each task only once and filled in two questionnaires. A statistical analysis was made and results from both groups were compared with the Mann-Whitney $U$-test, considering significant differences when $P \leq 0.05$. Interual consistency of the system has been analyzed with the Cronbach's alpha test.

Results Novices and experts positively rated SINERGIA characteristics. At least one of the evaluated metrics of each exercise presented significant differences between both groups. Nevertheless, all metrics under study gave a better punctuation to the executions accomplished by experts (lower time, higher efificiency, fewer errors...) than to those made by novices.
\end{abstract}

Conclusion SINERGIA laparoscopic virtual reality simulator is able to discriminate subjects according to their level of experience in laparoscopic surgery; therefore, it can be used within a training program as an assessment tool.

Keywords Laparoscopy - Simulator - Validation . Virtual reality · Minimally invasive surgery

\section{Introduction}

Laparoscopic surgery has gone over conventional surgery till the point that it is currently used in many surgical procedures as it can be applied in all surgical techniques [1-4]. Laparoscopic surgery provides several advantages for the patient [5-7]. Nevertheless, it also presents a certain number of difficulties due to its nature as it requires the training of new technical skills. This characteristic implies a longer learning curve to achieve the necessary skills and cognitive learning [8].

In this leaning process, laparoscopic simulation has become a fundamental element $[9,10]$. There are different kinds of simulators based on different technologies. A main division between physical and virtual simulators can be established. Ones of the most used simulators among physical traiuers are the box traiuers [11]. These simulators are used to lean basic skills thauks to its low cost aud simple maiutenauce. However, these simulators have some limitations. The main one, apar from that it is not possible to implement complex procedures, is that evaluation is iu most cases subjective as it is performed by the observation of an expert and the evaluated metrics are reduced to time aud uunber of errors. Nowadays, some works have been developed to improve physical simulator by including substantial changes 


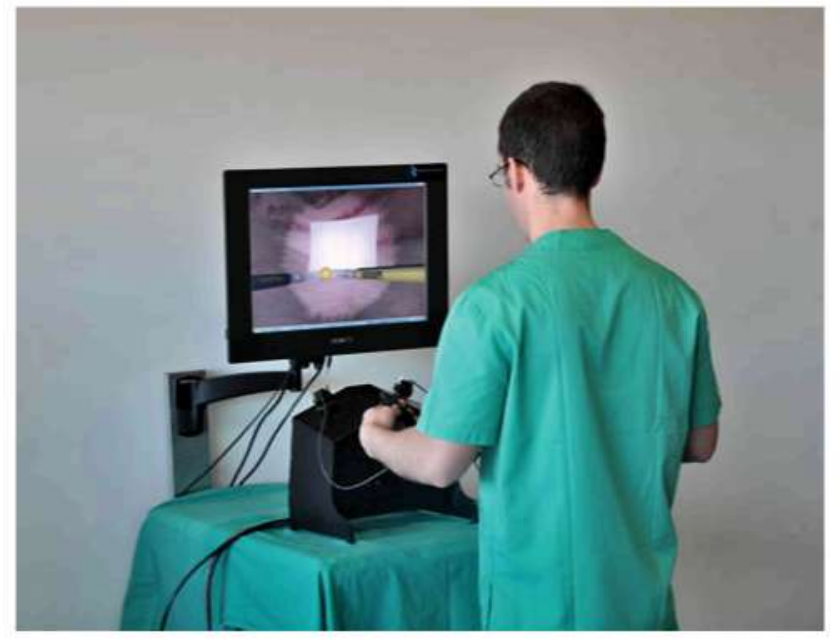

Fig. 1 SINERGIA laparoscopic virtual reality simulator

such as the addition of augmented reality. This results in a higher number of evaluated metrics that are also objective [12].

Virtual simulators are based on virtual reality (VR). This kind of simulators can evaluate all metrics in an objective way without the need of an expert revising and evaluating the execution of the different tasks. Therefore, this kind of simulators allows the automation of the process by including tutorials that describe the correct realization of the tasks even with images from original videos of the tasks themselves. These tutorials can substitute in some cases the presence of a mentor. Virtual simulators try to solve the problems associated with subjectivity of physical simulators, but they present other inconveniences such as the lack of realism and their high cost in most cases.

The objective of this paper is to show the face and construct validity $[13,14]$ of SINERGIA laparoscopic VR simulator (Fig. 1). SINERGIA is a VR simulator designed and developed for the learning of basic skills in laparoscopic surgery. Two main contributions arise from this global aim: (1) a specification of didactic exercises that has reverted into the creation of a new training environment; (2) an appropriate use of simulation technologies that has significantly improved the whole simulation. The simulator comprises 7 didactic units: hand-eye coordination, camera manipulation, grasping, pulling, cutting, dissection and suture [15]. A fundamental step in simulators validation is to evaluate whether it is sensitive enough to distinguish between subjects with different level of experience. Therefore, this work has been focused in checking if SINERGIA is able to discriminate novices and experts with different experience in laparoscopic surgery with the purpose of defining the objectives of a future wider study.

\section{Materials and methods}

This study validates SINERGIA laparoscopic virtual reality simulator: face and construct validity. It also determines the internal consistency of metrics that are common to all tasks.

\section{Subjects}

The total number of recruited participants in the study was twenty. All participants were included in the face validity study. A division into two subject groups was made to accomplish the study of construct validity. The division criterion was the subject experience in laparoscopic surgery. Group 1 was composed by fourteen novices (twelve female, two male) and group 2 comprised six experts (two female, four male). The mean age of the groups was $27 \pm 5.42$ years (range 23-38 years) for novices and $32.17 \pm 5.56$ years (range 27-39 years) for experts. All participants in the study were right-handed except one expert who was ambidextrous. None of the novices had previous experience in virtual reality simulators and only two of the experts had.

All tests were accomplished in the Minimally Invasive Surgery Centre in Cáceres, Spain. Experts had experience of more than 100 cases in laparoscopic surgery. All novices had attended laparoscopic procedures with minimal handson experience in camera guidance. Some of the novices had experience with videogames.

\section{Methodology}

Among all tasks that SINERGIA provides, five have been selected for this study. The rest have been omitted due to subject time considerations. These tasks are focused to enhance the most basic skills. The five selected tasks are (Fig. 2):

Task 1: Coordination. The aim is to touch a certain number of static spheres that appear sequentially in an "organic scene" with the left or right instrument according to the color of the sphere. There is a time limit to touch each ball. This time decreases each time that a ball appears.

Task 2: Navigation. The user has to center an endoscope sight in spheres that sequentially appear in the scene in a random position. There is a time limit to center each sphere. In this task, the camera is simulated with the left instrument.

Task 3: Navigation and touch. This task is based on the previous one and consists of centering an endoscope sight in a sphere and once it is centered, touching it with the opposite tool. Spheres appear sequentially and in random positions. There is a time limit to center and touch each sphere. In this task, the camera is simulated with the left instrument. 
Fig. 2 SINERGIA tasks that are considered in this study

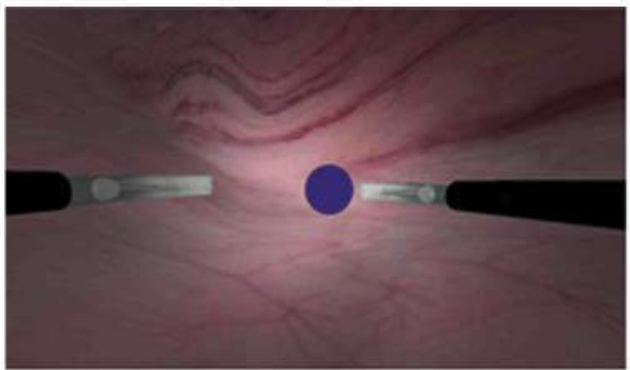

Task1 Coordination

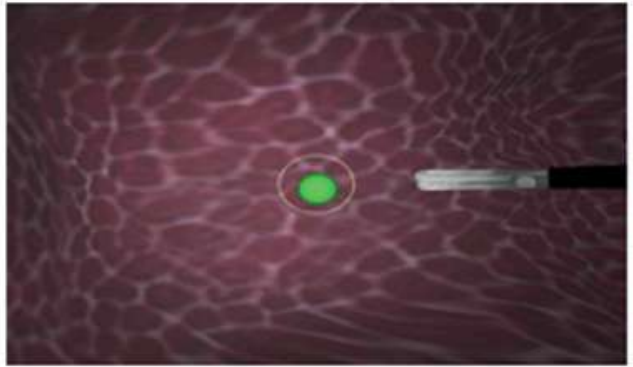

Task 3: Navigation and touch

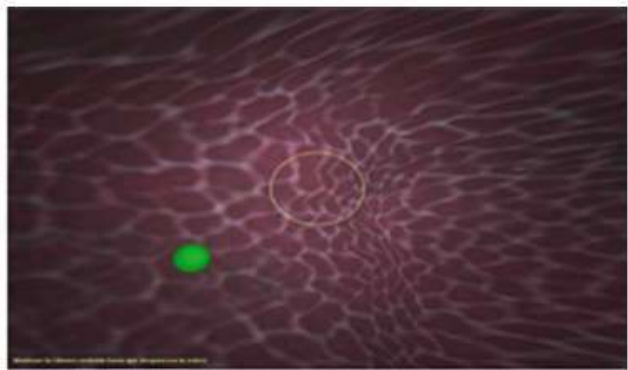

Task 2: Navigation

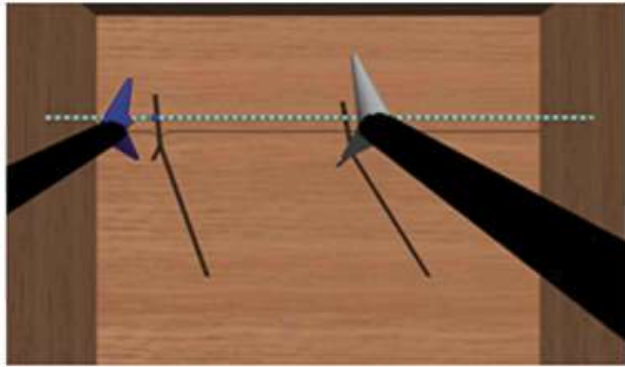

Task 4: Accurate grasping

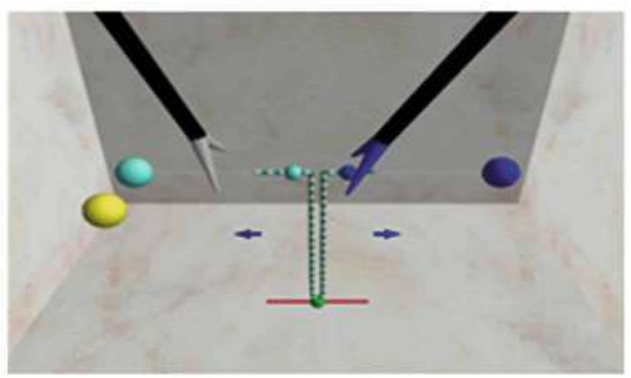

Task 5: Coordinated puliing

Task 4: Accurate grasping. The objective is to grasp a thread within a marked area without causing deformations to the thread. Grasping areas appear sequentially and depending on its color will have to be grasped with the right or left instrument. There is a time limit to grasp the point.

Task 5: Coordinated pulling. The aim is to grasp a thread at the marked points and pull them at the same time toward two big spheres following the white path. A "coordination-control bar" provides formative feedback when there is no coordination between both instruments, i.e. it is initially horizontally placed and keeps that position if both ends of the thread are pulled simultaneously; otherwise it leans. Three threads appear sequentially, each one in a different plane.

For each of these tasks, a certain number of metrics have been automatically recorded. Some parameters are common between tasks, whereas other metrics are specific to certain tasks. Metrics are defined as follows:

- Total time. Time that the user needs to accomplish the task
- Partial time. Mean time that the user needs to accomplish a partial task, i.e. touching a sphere in task 1 , centering a sphere in tasks 2 and $3 . .$.

- Fulfilment. Percentage of partial tasks done within the established time

- Efficiency. Ratio between the minimum distance and the actual distance to accomplish the task. It is measured both for right and left hand instrument, except for tasks 2 and 3 where only the left instrument efficiency is recorded.

- Harm to background. Number of times that the background is touched by any of the instruments.

- Deviation from the center point. Mean value of the distance between the middle point of the marked area and the actual grasped point.

- Grasping out of the area. Times that the thread is grasped out of the defined area.

- Grasping with excessive pressure. Times of grasps that applies an excessive deformation to the thread.

- Distance to the ideal path. Distance between the ideal traction line and the actual described line.

- Non-coordination moments. Times that the coordinationcontrol bar gets vertical. 
Table 1 Automatically evaluated metrics in SINERGIA divided by tasks

\begin{tabular}{|c|c|c|}
\hline Task & Description & Metrics \\
\hline Coordination & $\begin{array}{l}\text { Touching static spheres that appear } \\
\text { sequentially in an "onganic scene". } \\
\text { There is a time himit to touch each } \\
\text { sphere }\end{array}$ & $\begin{array}{l}\text { Total time (s) } \\
\text { Partial time (s) } \\
\text { Fulfilment (\%) } \\
\text { Left instrument efficiency (\%) } \\
\text { Right instrument efficiency (\%) } \\
\text { Harm to background (\#) }\end{array}$ \\
\hline Navigation & $\begin{array}{l}\text { Centering an endoscope sight in spheres } \\
\text { that sequentially appeat. There is a time } \\
\text { limit to center each sphete. }\end{array}$ & $\begin{array}{l}\text { Total time (s) } \\
\text { Partial time (s) } \\
\text { Fulfilment (\%) } \\
\text { Left instrument efficiency (\%) } \\
\text { arn to background (\#) }\end{array}$ \\
\hline Navigation and touch & $\begin{array}{l}\text { Centering an endoscope sight in a sphere } \\
\text { and once it is centered, touching it with } \\
\text { the othet tool. Spheres appeat } \\
\text { sequentially. There is a time limit to } \\
\text { center and touch each sphere. }\end{array}$ & $\begin{array}{l}\text { Total time (s) } \\
\text { Partial time (s) } \\
\text { Fulfillment (\%) } \\
\text { Left instrument efficiency (\%) } \\
\text { Harm to backgtound ( }(\%)\end{array}$ \\
\hline Accurate grasping & $\begin{array}{l}\text { Grasping certain points of a thread } \\
\text { without causing deformations to it. } \\
\text { Grasping areas appear sequentially. } \\
\text { There is a time limit to grasp the point. }\end{array}$ & $\begin{array}{l}\text { Total time }(\mathrm{s}) \\
\text { Partial time }(\mathrm{s}) \\
\text { Fulfillment }(\%) \\
\text { Deviation from the center point (cm) } \\
\text { Left instrument efficiency }(\%) \\
\text { Right instrument efficiency }(\%) \\
\text { Grasping out of the area }(\$) \\
\text { Grasping with excessive pressure }(\boldsymbol{})\end{array}$ \\
\hline Coordinated pulling & $\begin{array}{l}\text { Grasping a thread at the marked points and } \\
\text { pull them following the white path until } \\
\text { the big spheres. A "coordination-control } \\
\text { bat" provides formative feedback. }\end{array}$ & $\begin{array}{l}\text { Total time }(s) \\
\text { Parrial time }(s) \\
\text { Fulfillment }(\%) \\
\text { Left instrument distance to the ideal path }(\mathrm{cm}) \\
\text { Right instrument discance to the ideal path }(\mathrm{cm}) \\
\text { Left instrument efficiency }(\%) \\
\text { Right instrument efficiency }(\%) \\
\text { Non-coordination moments (\#) }\end{array}$ \\
\hline
\end{tabular}

Which metrics are recorded for each task is shown in Table 1. Common metrics are total time, fulfllment and instrumental efficiency. Path length is also recorded by the simulator, but it has not been included in the studio. Although this metric is quite intuitive, it is not useful to compare as it is highly dependent on the position of the elements, which are randomly situated on the scene. Therefore, efficiency is more recommended as the effects of the random positions are avoided.

In order to obtain a proper performance, one research assistant gave all subjects a brief explanation of the rules of each task before they taced SINERGIA. Subjects were supervised while they were doing the tasks, but they did not receive any external help. Each subject performed each task only once and filled in demographic and face validity questionnaires just after the testing. All snbjects accomplished the tasks in the order they are described earlier and consecntively, withont breaking time in between the tasks.

\section{Questionnaires}

All subjects were requested to fill in two questionnaires. The first questionnaire comprised demographic, laparoscopic experience and videogames experience questions. The second one referred to characteristics of SINERGIA that the subjects had to rate. These questions had to be answered in a 5-point Likert scale. Finally, an open-ended question for commentaries closed the second questionnaire. 
Table 2 Face validity questionnaire results

Significant difterences are consider for $P<0.05$

a Significance is calculated with

the Mann-Whitney U-test

\begin{tabular}{llll}
\hline Characteristics & Novices $(n=14)$ & Experts $(n=6)$ & $P$ value $^{3}$ \\
\hline Realism & $3.57 \pm 0.64$ & $3.33 \pm 0.73$ & 0.547 \\
Haptic sensation & $3.07 \pm 0.73$ & $2.83 \pm 0.75$ & 0.547 \\
Instrument movement & $3.79 \pm 0.80$ & $3.50 \pm 0.84$ & 0.602 \\
Abdominal cavity anatony & $3.57 \pm 0.76$ & $3.50 \pm 0.56$ & 0.841 \\
Range of tasks & $4.00 \pm 0.39$ & $3.67 \pm 0.56$ & 0.312 \\
Usefulness of the evaluation of SINERGIA & $3.86 \pm 0.77$ & $3.83 \pm 0.75$ & 0.968 \\
Usefulness to learn basic skills & $4.14 \pm 0.53$ & $4.00 \pm 0.63$ & 0.718 \\
\hline
\end{tabular}

Statistical analysis

Statistical analysis was performed nsing SPSS software (version 15.0 for Windows, SPSS Inc., Chicago, IL). Data are expressed in terms of mean \pm standard deviation. Data from the two groups are compared with the Mann-Whitney $U$-test. Differences were considered significant at $P \leq 0.05$.

Reliability is a measnre of internal consistency of the system. For that purpose, melrics that are common between all tasks have been analyzed with the Cronbach`s alpha test.

\section{Results}

Face validity

As Table 2 shows, there is no significant difference in the experts and novices opinion with respect to SINERGIA characteristics. The most valued aspect by the experts is SINERGIA usefulness to train basic skills, considering it good or very good by $83 \%$ of subjects, and the haptic sensation gets the lowest score as only $17 \%$ of them consider it as very good. Novices agree with experts giving the lowest punctuation to the haptic sensation (it is good for $29 \%$ of the novices) and positively rate SINERGIA as a training tool, rated as good or very good by $92 \%$ of novices, as well as the range of exercises (mean score of 4 by $86 \%$ of the novices). Neither novices nor experts consider any of the characteristics as bad or very bad (mean score under 2).

\section{Construct validity}

Table 3 shows the results of the Mann-Whitney tests for the analyzed groups (novices and experts). All metrics for each task have been included in the Table. At least one of the metrics of each task presents significant differences, but it is only navigation and touch task the one that differentiates between experts and novices in all the evaluated parameters. There were significant differences between the experienced group and non-experienced group in the task 3. A common characteristic among all tasks is that metrics that score the number of errors (harm to background or moments of non-coordination) shows important differences between both groups.

As previonsly described in the methodology, metrics that are evaluated in all tasks are total time, partial time, fulfilment and left instrument efficiency. They all give a better punctnation to executions accomplished by experts than to the ones accomplished by novices, althongh not always the same metric presents significant differences for different tasks. Figures 3-6 show the obtained values per metric by novices and experts for each one of the tasks. Horizontal bands indicate medians, boxes indicate 25th and 75th percentiles and whisker lines indicate highest and lowest values. Total time shows significant differences in tasks 1, 3 and 4; fulfilment in tasks 3 and 5 and lefi instrumental efficiency in tasks 2,3 and 5 .

\section{Reliability}

Results of reliability shows that total and partial time obtain the lowest results for $\alpha$. Among the rest of metrics, just lefi instrument efficiency obtain a level higher than the desired $\alpha=0.70$ and fulfillment is pretty close to it (see Table 4 ).

\section{Discussion}

Laparoscopic surgery simulators are more and more important within the formative process of surgeons in laparoscopic surgery. They are a decisive tool in the first steps of the learning method. Many are simulators involved in this apprenticeship, from basic box trainers to sophisticated virtual reality simulators. A validation of simulators is always necessary in order to determine their capacity for surgeons training although as far as we know, there is not any mandatory validation strategy [14]. Construct validity is one of the steps included in the validation of any simulator. This kind of validation consists on determining whelher the simulator punctuates the execution according to the level of experience of the subject who is accomplishing the task. So, a construct validated simulator will be able to distinguish between surgeons with different levels of skill in laparoscopic surgery. 
Table 3 Metrics tesults for novices and experts

\begin{tabular}{|c|c|c|c|c|}
\hline Tasks & Metrics & Novices $(n=14)$ & Expens $(n=6)$ & $P$ value \\
\hline \multirow[t]{6}{*}{ Coordination } & Total time (s) & $75.16 \pm 9.72$ & $61.97 \pm 11.11$ & $0.033^{\text {* }}$ \\
\hline & Partial time (s) & $2.98 \pm 0.49$ & $2.48 \pm 0.45$ & 0.062 \\
\hline & Fulfillment (\%) & $75.14 \pm 8.18$ & $85.33 \pm 8.26$ & 0.051 \\
\hline & L-I efficiency (\%) & $36.80 \pm 11.48$ & $46.97 \pm 10.67$ & 0.062 \\
\hline & R-I efficiency (\%) & $37.06 \pm 8.48$ & $47.27 \pm 10.78$ & $0.033^{*}$ \\
\hline & Harms to background (\#) & $11.43 \pm 5.45$ & $4.67 \pm 2.88$ & $0.006^{*}$ \\
\hline \multirow[t]{5}{*}{ Navigation } & Total time (s) & $104.71 \pm 10.95$ & $97.50 \pm 12.93$ & 0.353 \\
\hline & Partial time (s) & $7.86 \pm 0.73$ & $7.36 \pm 0.57$ & 0.207 \\
\hline & Fulfillment (\%) & $76.36 \pm 14.48$ & $88.00 \pm 8.39$ & 0.076 \\
\hline & L-I efficiency (\%) & $40.93 \pm 8.19$ & $47.52 \pm 3.89$ & $0.033^{*}$ \\
\hline & Harms to background (\#) & $0.29 \pm 0.61$ & $0.67 \pm 0.82$ & 0.353 \\
\hline \multirow[t]{5}{*}{ Navigation and touch } & Total time (s) & $106.79 \pm 19.92$ & $85.33 \pm 11.36$ & $0.005^{*}$ \\
\hline & Partial time (s) & $7.48 \pm 1.27$ & $5.97 \pm 0.92$ & $0.007^{*}$ \\
\hline & Fulfillment (\%) & $71.64 \pm 15.83$ & $95.50 \pm 4.93$ & $0.007^{*}$ \\
\hline & L-I efficiency (\%) & $40.93 \pm 10.03$ & $55.45 \pm 3.84$ & $0.014^{*}$ \\
\hline & Harms to background (\#) & $95.36 \pm 94.01$ & $11.33 \pm 4.46$ & $0.002^{*}$ \\
\hline \multirow[t]{8}{*}{ Precise grasping } & Total time (s) & $50.14 \pm 12.66$ & $32.50 \pm 5.58$ & $0.002^{\text {* }}$ \\
\hline & Partial time (s) & $5.01 \pm 1.30$ & $3.27 \pm 0.52$ & $0.002^{*}$ \\
\hline & Fulfillment (\%) & $100.00 \pm 0.00$ & $100 \pm 0.00$ & 1 \\
\hline & Deviation from the central point $(\mathrm{cm})$ & $0.06 \pm 0.01$ & $0.04 \pm 0.01$ & $0.003^{*}$ \\
\hline & L-I efficiency (\%) & $6.43 \pm 2.62$ & $8.33 \pm 2.16$ & 0.091 \\
\hline & R-I efficiency (\%) & $8.21 \pm 2.75$ & $10.17 \pm 3.54$ & 0.207 \\
\hline & Grasps out of the area (\#) & $4.71 \pm 6.39$ & $1.00 \pm 1.26$ & $0.02 *$ \\
\hline & Grasps with excessive pressure ( & $3.00 \pm 2.08$ & $0.00 \pm 0.00$ & $0.002^{*}$ \\
\hline \multirow[t]{8}{*}{ Coordinate Traction } & Total time $(s)$ & $123.71 \pm 45.41$ & $87.00 \pm 24.58$ & 0.051 \\
\hline & Partial time (s) & $41.33 \pm 15.24$ & $29.11 \pm 8.32$ & 0.062 \\
\hline & Fulfillment (\%) & $69.05 \pm 20.52$ & $94.44 \pm 13.61$ & $0.026^{*}$ \\
\hline & L-I discance from the ideal hine (cm) & $836.93 \pm 352.73$ & $501.33 \pm 201.78$ & $0.02 *$ \\
\hline & R-I discance from the ideal hine (cm) & $748 \pm 285.64$ & $504.67 \pm 184.19$ & $0.041^{*}$ \\
\hline & L-I efficiency $(\%)$ & $4.31 \pm 1.03$ & $6.61 \pm 1.42$ & $0.002 *$ \\
\hline & R-I efficiency (\%) & $5.10 \pm 1.66$ & $7.11 \pm 2.22$ & 0.062 \\
\hline & Non-coordinarion moments ( $\$$ ) & $31.64 \pm 36.56$ & $1.33 \pm 3.27$ & $0.001^{*}$ \\
\hline
\end{tabular}

Data are expressed in terms of mean score \pm standard deviation

a Significance is calculated with the Mann-Whitney $U$-test

* Signilicant differences when $P<0.05$

Previously to the construct validity, the face validity can be evaluated. This kind of validation is just based on the opinion and experience of surgeons and cannot be used in any case to define the validity of a new simulator. As the face validity is very subjective, it is usually used at the first stages of validation [14]. We will assess characteristics of SINERGIA simulator such us realism or haptic sensation by means of a face validity test.

The objective of this paper is to validate SINERGIA laparoscopic virtual reality simulator by accomplishing a face and construct validity in order to determine whether it is adequate for basic skills training.
Survey results confirm that novices and experts agree in the assessment of SINERGIA simulator, without significant differences in any of the evaluated aspects. Both groups consider the most remarkable characteristic the usefulness as a learning tool for basic laparoscopic skills, rating the simulator as very good. The characteristic that is worse scored is the haptic sensation, which is considered as bad by experts and acceptable by novices. Nevertheless, VR simulators usually present this kind of problems, as incorporating realistic haptic feedback into these systems is complicated [16]. Realisin is scored as neutral, but considering that SINERGIA does not represent a real surgical environment in most of the tasks, 


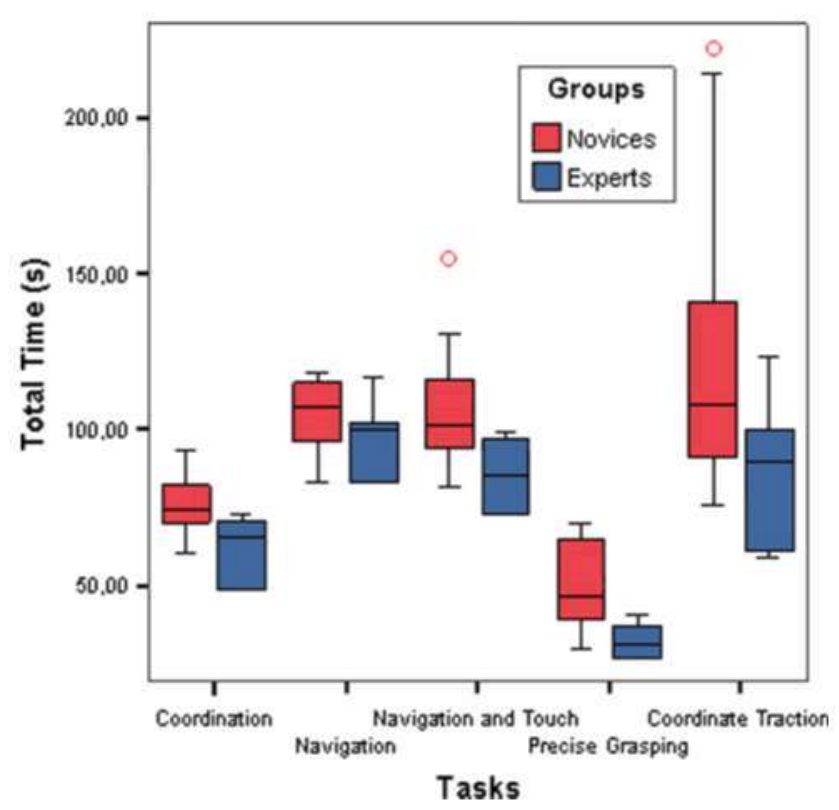

Fig. 3 Comparison of the metrics between novices and experts groups for total time to finish the task ( $\mathrm{sec}$ )

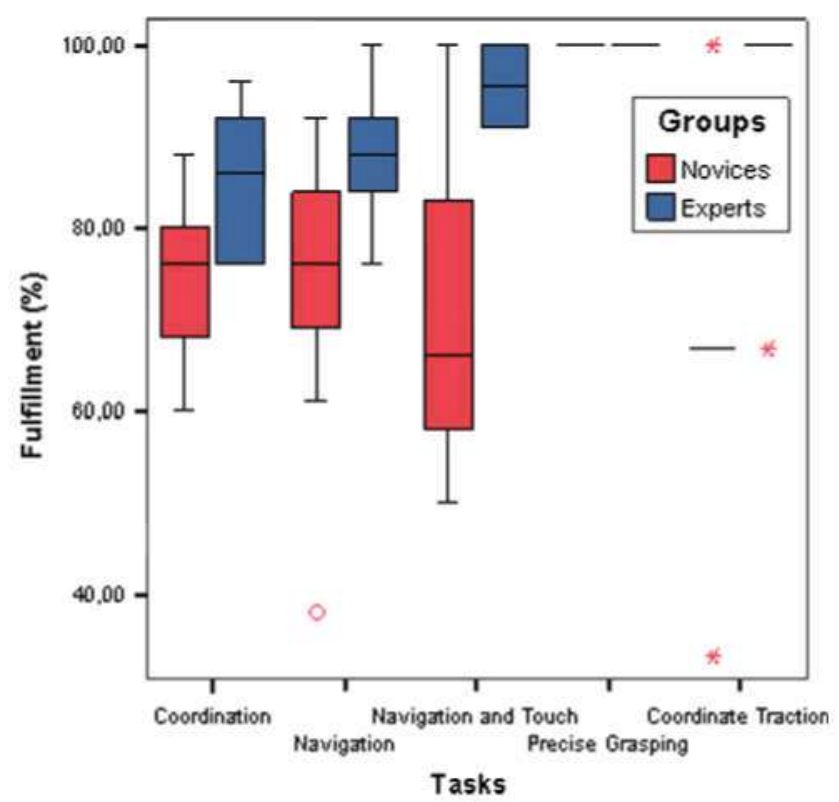

Fig. 4 Comparison of the metrics between novices and experts groups for fulfillment (\%)

it is coherent that users do not consider it realistic. The rest of evaluated characteristics get punctuations higher than 3.33 , therefore the mean assessment of SINERGIA can be considered acceptable.

The results of the study show that there are significant differences between the execution of tasks by novices and by experts for the evaluated metrics. Of the proposed metrics, $59.36 \%$ are sensitive enough to discriminate between both groups with significant differences. Nevertheless, although

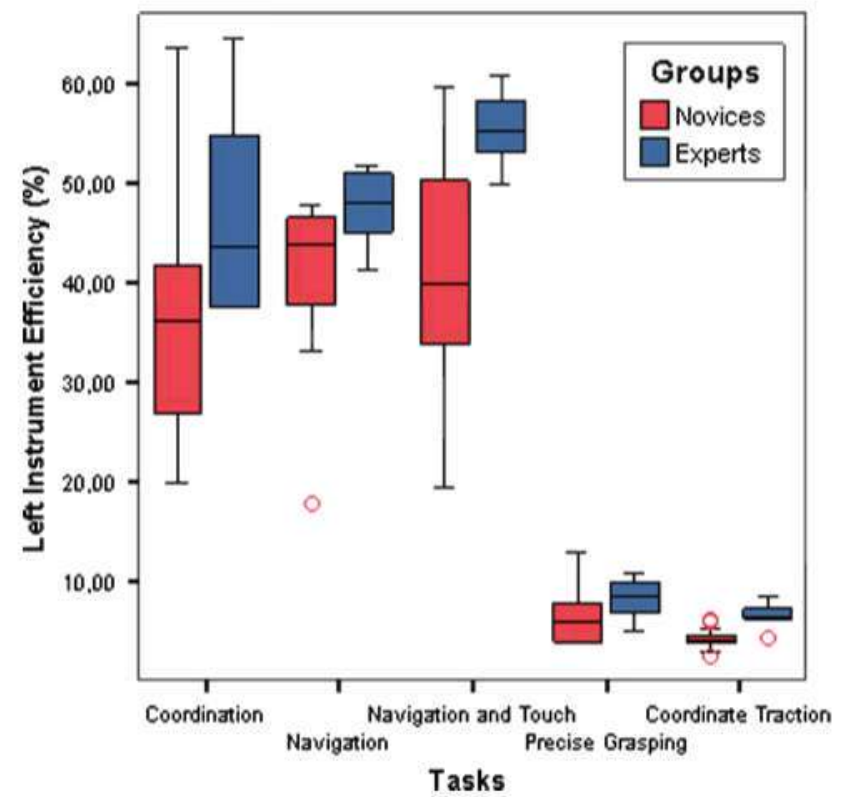

Fig. 5 Comparison of the metrics between novices and experts groups for left instrument efficiency (\%)

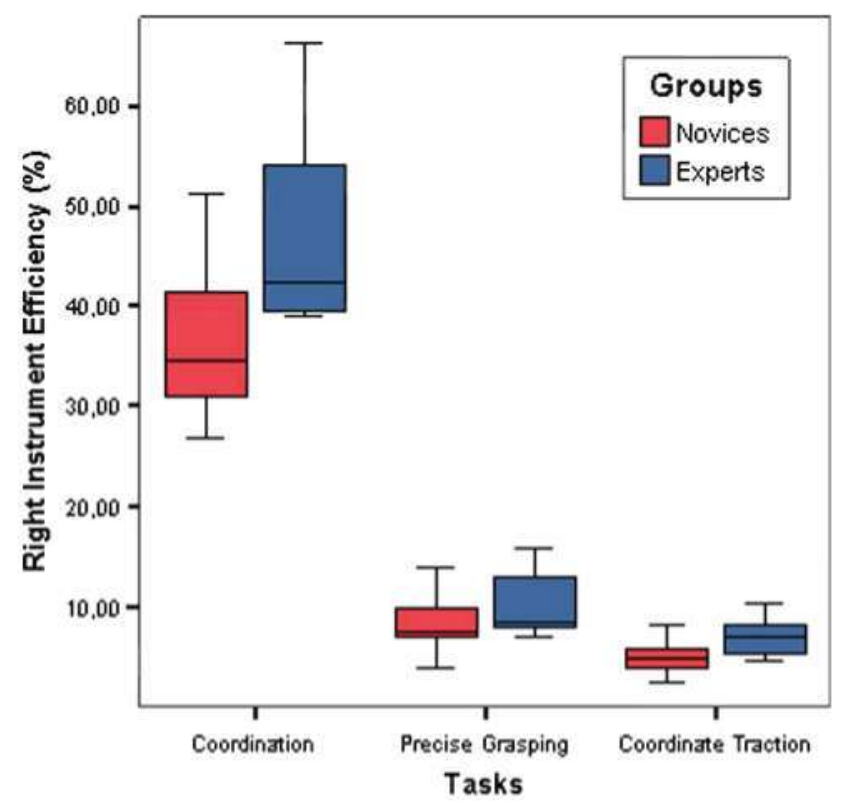

Fig. 6 Comparison of the metrics between novices and experts groups for right instrument efficiency (\%)

the rest of metrics do not present significant statistical differences, in all cases experts get a better punctuation than novices.

Among all evaluated tasks, navigation and touch is the one that shows better results, distinguishing in all its metrics the level of skills of the subjects. After finishing all tasks included in the study, all participants agreed on pointing out navigation and touch as the most difficult task. The very significant differences confirm the subjects' opinion when 
Table 4 Cronbach's alpha test results for metrics that are common to all casks

"Only consider coordinarion. precise grasping and coordinate traction tasks

\begin{tabular}{ll}
\hline Metric & $\alpha$ \\
\hline Total time & 0.461 \\
Partial time & 0.102 \\
R-instrument efficiency & 0.479 \\
L-instrument efticiency & 0.706 \\
Fulfillment & 0.659 \\
\hline
\end{tabular}

defining it as the most difficult one although it is a basic skill task.

Navigation task does not present any difference between the different levels of experience except for instrument efficiency. This result can be due to the fact that novices do not have experience in accomplishing tull surgical procedures, but they do have experience in camera handling.

It is interesting to remark in this results analysis the metric fulfllment of precise grasping. All subjects obtain the same results, without relation to the level of experience. This can be due to the high time limit established for each grasping. Nevertheless, the difference between novices and experts is evident in the rest of evaluated metrics, mainly in the total time necessary to finish the tasks and the committed errors due to grasping out of the defined area.

Finally, coordinate traction task show significant differences for the most part of its metrics except for the total time. This is due to the aim of the task is not finishing the task in a short time but keeping the coordination between both hands during the whole exercise. The metric that evaluates the noncoordination moments presents high significant differences $(\boldsymbol{P}<0.01)$.

Two of the most common criteria to determine the level of experience of a surgeon are total time and number of errors. In all analysed tasks, there is at least one metric that points out the committed errors and all of them, except in navigation task, show significant differences between the groups under study.

Metrics that are evaluated in all tasks (total time, partial time, fulfllment and lefi instrument efficiency) give a better punctuation to executions accomplished by experts than to the ones accomplished by novices. Novices need more time than experts to finish the tasks in all cases and experts fulfill more part of the tasks and more efficiently than novices in all cases. Nevertheless, the same metric evaluated in different tasks results in different outcomes when referring to differentiate novices and experts. Meanwhile, total time is useful to distinguish between novices and experts in tasks 1, 3 and 4 , they are not able to discriminate both groups in tasks 2 and 5 .

Therefore, one single metric is not enough to discriminate novices and experts in all tasks. These two facts lead us to the conclusion that a global score could be calculated. Each met- ric wonld contribute to a greater or lesser extend depending on its capacity to distingnish between novices and experts for a specific task. This conclnsion is also supported by Heinrichs et al. [17] and will be considered in future works.

Resnlts of internal consistency confirms that total and partial time are highly dependent on the tasks which lead to low valnes of $\alpha$; meanwhile, L-Instrument efficiency and filfillment present good reliability among all evaluated tasks.

In conclusion, SINERGIA laparoscopic virtual reality simulator is able to distinguish between subjects with different level of laparoscopic experience (novices and experts) in almost $60 \%$ of the evaluated metrics. Therefore, it could be said that partial construct validity is reached. Commercial VR simulators such us Simbionix LAPMentor, Delltech Simendo or Haptica ProMIS have been broadly validated by several authors and not all studies can asses total constnuct validity [18]. This conclusion leads us to the point that SINERGIA could be used in training programs as an assessment tool.

Nevertheless, the limited size of the sample for this study implies that this last conclusion should be checked again with a wider number of subjects, using the results of this preliminary study to define clear and valid objectives for the second study, as Molina et al. did in [19]. It is also important to consider three different levels of experience (novices, intermediate and experts) in the future work. We are confident that future studies will confirm this statement with the purpose of using SINERGIA within a training curriculum.

Finally, it is also considered as iuture work whether it is possible to establish a benchmark that novices should obtain after training and whether the scores obtained by experts could be the values of this mentioned benchmark.

Acknowlexlgments This work has been funded by SINERGIA Cooperative Network (G03/135) from the Ministerio de Sanidad y Consumo. Spain.

\section{References}

1. Yamaguchi S, Koníshi K, Yasunaga $T$, Yoshida D, Kinjo N. Kobayashi K. Ieiri S, Okazaki K. Naksshima H. Tanoue K. Maehata Y. Hashizume M (2007) Construct validity for eye-hand coordination skill on a vinual reahity lapanoscopic surgical simulator. Sung Endosc 21(12):2253-2257

2. McDougall EM. Clayman RV, Elashry OM (1999) Laparoscopic radical nephrectomy for renal tumot: the Washington University experience. J Utol 155: 1 180-1185

3. McDougall EM. Clayman RV, Elashry OM (1995) Laparoscopic nephroureterectomy for upper tract transitional cell cancer: Washington University experience. J Utol 154:975-980

4. Priego P, Lobo E, Rodriguez G, Cabañas M, Peromingo R, Fresnada V (2008) Es adecuoda la formación del residente en cirugía laparoscópica. Rev Chilena de Cirugía 60(5):418-423

5. Botden SM, Jakimowicz JJ (20)9) What is going on in augmented teality simularion in laparoscopic surgery? Surg Endosc August 23(8): $1693-1700$ 
6. Macintyre IM, Wilson RG (1993) Laparoscopic cholecystectomy. Br J Surg 80(5):552-559

7. Grace PA, Quereshi A. Coleman J, Keane R, McEntee G, Broe P, Osborne H. Bouchuier-Hayes D (1991) Reduced postoperative hospitalization afier lapanoscopic cholecystectomy. Br J Surg $78: 160-162$

8. Rodríguez JI, Turienzo E, Vigal G, Brea A (2006) Formación quirúngica con simuladores en centros de entrenamiento. Cir Esp $79(6) \div 342-348$

9. Fried GM, Feldman LS, Vassiliou MC. Fraser SA. Stanbridge D. Ghitulescu G. Andrew CG (2004) Proving the value of simulation in laparoscopic surgery. Ann Surg 240(3):518-525; discussion $525-528$

10. Andrearta PB, Woodrum DT, Birkmeyer JD. Yellamanchilli RK. Doheny GM, Gauger PG, Minter RM (2006) Laparoscopic skills are improved with LapMentor training: results of a randomized, double-blinded study. Ann Surg 243(6):854-863

11. Dhariwal AK, Ptabhu Ramkrishna Y, Dalvi Abhay N. Supe Avinash N. (2007) Effectiveness of box trainers in laparoscopic training. J Minimal Access Surg 3:57-63

12. Young D, Slevin F, Cassidy D, Ryan D (2007) Objective measurement of FLS ptecision cutting task. SAGES ETP057

13. McDougall EM (2007) Vahidation of surgical sinulators. J Endourol 21(3):244-247
14. Gallagher AG. Ritter Em. Satava RM (2003) Fundamental pinciples of validacion, and tealiability: rigonous science for the assessment of surgical education and training. Surg Endosc 17:15251529

15. Lamata P. Gómez E, Sánchez-Margallo F. López O, Monsettar C, García V. Alberola C. Rodríguez Florido M. Ruiz J. Us6n J (2007) Sinergia laparoscopic virtual reality simulador: didactic design and technical development. Comput Methods Programs Bioned $85(3): 273-283$

16. Lamata P, Gómez EJ. Sánchez-Margallo FM et al (2005) Study of laparoscopic forces perception for defining simulation fidelity. Stud Health Technol Inform 119:288-292

17. Heinrichs WL, Lukofl B. Youngblood P, Dev P, Shavelson R, Hasson HM. Sacava RM. McDougall EM. Werter PA (2007) Criterion-based training with surgical simulators: profiency of experienced surgeons. JSLS 11(3):273-302

18. Thijssen AS, Schijven MP (2009) Contemporary virtual reality laparoscopic simulators: quicksand ot solid grounds for assessing surgical trainees? doi: $10.1016 /$ j.amjsurg.2009.04.015

19. Molina CR, de Win G, Ritter O, Keckstein J, Miserez M. Campo R (2008) Feasibility and construct validity of a novel laparoscopic skills testing and training model. Gynecol Surg 5(4): 281-290 